\title{
The Climate Characteristics and Forecast of Fog in Shanxi Province
}

\author{
Jun-Hui LEI ${ }^{1,{ }^{*}}$, Jin-Hong ZHOU ${ }^{1}$ and Xiao-Ting TIAN $^{1}$ \\ ${ }^{1}$ Taiyuan Meteorological Office of Shanxi Provice, Taiyuan 030000
}

\author{
Keywords: Fog; Climate characteristics; Circulation; Forecast; Shanxi Province
}

\begin{abstract}
Using the observed fog data in Shanxi Province during 1961 to 2010, the distribution and longtime variability trends have been analyzed. Results show that the fog mainly occurs in the southeastern areas and decreases towards northwest. 40 percent fogs have occurred in fall, 26 percent in summer. The trends of the annual fog occur days are positive. The circulation situation when fog occurs can be divided into four classes: two trough a ridge type (47\%), a trough a ridge type (9\%), broad low (40\%), two groove ridge (4\%). The forecast of fog can be predicted from the formation, maintenance and strengthening, attenuation and dissipation.
\end{abstract}

\section{The Introduction}

The fog is a large amount of small water droplets or ice crystals suspended in the air of the pasted strata, allowing the visibility to be less than $1 \mathrm{~km}$. Shanxi Province is a complex landscape, a base for coal and a variety of heavy industry industries, and it is a multi-site of smog, and the distribution of fog day is very different. With the rapid development of economy in Shanxi Province in recent years, highway, railway transport and air transport operation scope and density increased significantly, the influence of the fog is more and more prominent, the frequent occurrence of traffic accidents caused by fog. Therefore, the analysis of the characteristics of fog day and its influencing factors can improve the cognition of fog phenomena and improve the forecast and prevention ability of fog.

The study found that the fog in Shanxi Province can occur in any weather situation. The fog in Shanxi Province can occur all year round. The formation of the fog on the circulation situation and characteristics of some meteorological elements field have a certain similarity, forecasters in the actual operation is difficult to distinguish, so the forecast is very difficult.

\section{Data and Methods}

The data is from the meteorological information network center of the province, Shanxi Province. The fog observed data is during $1951 \sim 2010$. According to the meteorological observation specification, visibility is within $1 \mathrm{~km}$ of fog. In the case of the number of fogs in a certain station, the rule is that when the station is observed one day or more, it is a foggy day. Considering the low number of weather stations in the 1950s and the short sequence of some sites, the spatial and temporal characteristics and the statistical analysis of the spatial and temporal characteristics of 108 stations in $1961 \sim 2010$ were selected. According to the characters of terrain to the province is divided into three zones: the northern region (including datong,shuozhou,xinzhou), the central region (including Taiyuan, Luliang, Jinzhong, Yangquan), south region(including the Linfen, Yuncheng, changzhi, Jincheng).

The method used in this paper includes linear regression and correlation method, trend analysis and inspection using wavelet analysis to cycle and mutation analysis. 


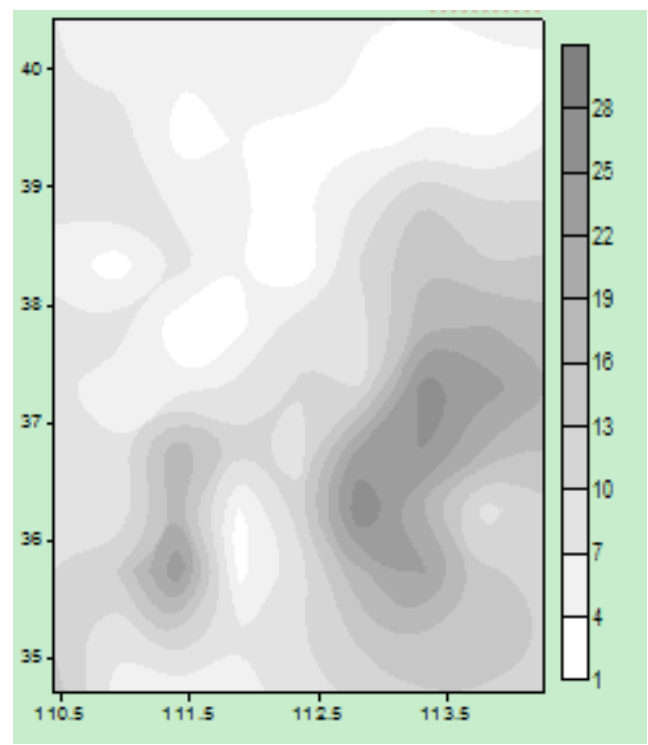

Fig.1 Average annual fog days (d) in shanxi Province in 1981-2010

\section{Climate Characteristics}

\section{Average Annual Fog Daily Distribution}

The difference between the number of years of the average annual fog is significant (figure 1), the southeast is more, the northwest is less, and generally the southeast is gradually decreasing to the northwest. The northwest area is a small fog area for the whole province, the fog day is less than $10 \mathrm{~d}$, the northwest of lu liang and the west of xinzhou are the least, between 1 and $5 \mathrm{~d}$. In other parts of the fog day in more than $10 \mathrm{~d}$, foggy area distribution in the southeast, including changzhi, jincheng, yangquan, fog day in more than $20 \mathrm{~d}$, including southern XiangFen fog day at most, luliang region of xingxian fog days at least.

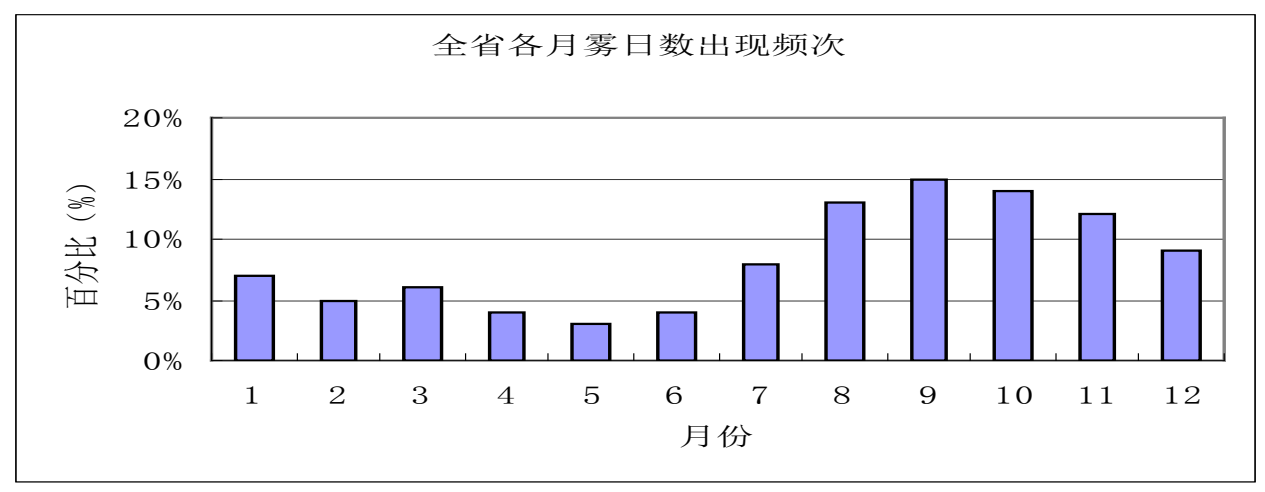

Fig.2 Monthly variation of average fog days of shanxi Province in 1981-2000

\section{The Fog Day is Characterized by Several Months}

In Shanxi Province, fog has occurred throughout the year, but mainly in the fall, about $40 \%$. The second is summer, accounting for $26 \%$; In the spring of the least; And individual stations (such as xingxian in central China) are mainly winter.

The province has the most fog day in September, followed by October and the fewest in April. 


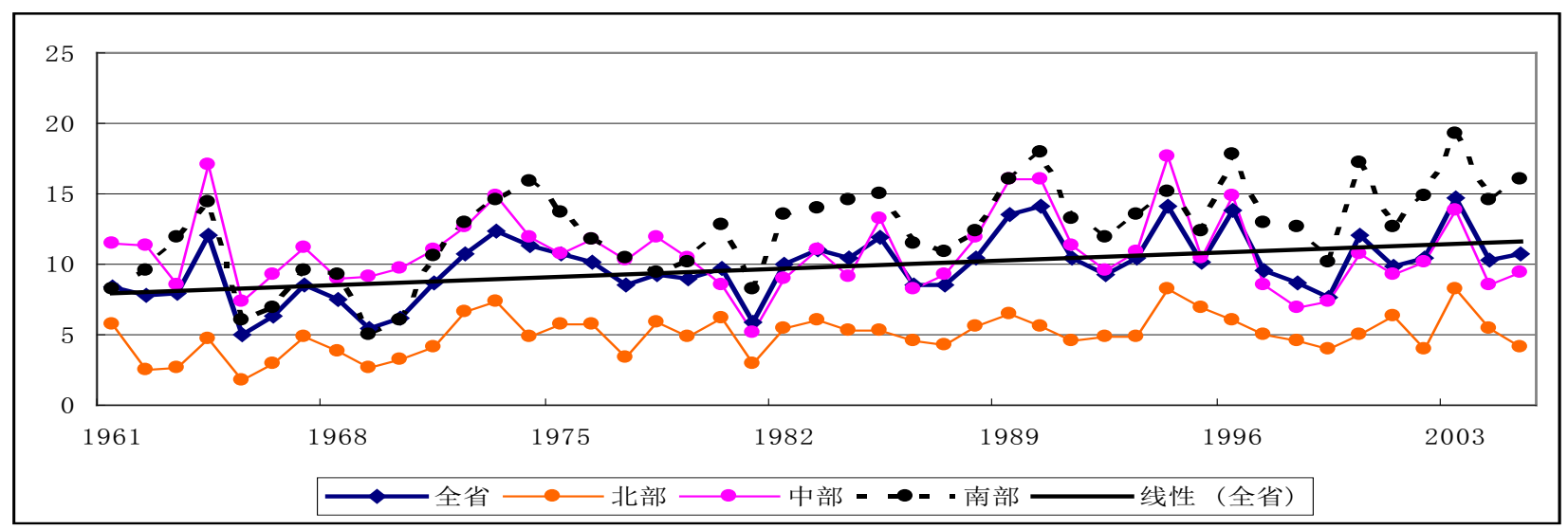

Fig.3 1961-2010 average fog day change trend

\section{The Annual Average Fog is Changing over the Years}

In the whole province, the average annual fog is increasing gradually.

From the linear trend line, the basic idea is that in 1984, it was divided into two periods, before the period of partial decline, and then the later period. In the north and south, there is a gradual increase, but the south is growing faster. The increase of the average mist day in the province is mainly caused by the increase in the number of fogs in the south.
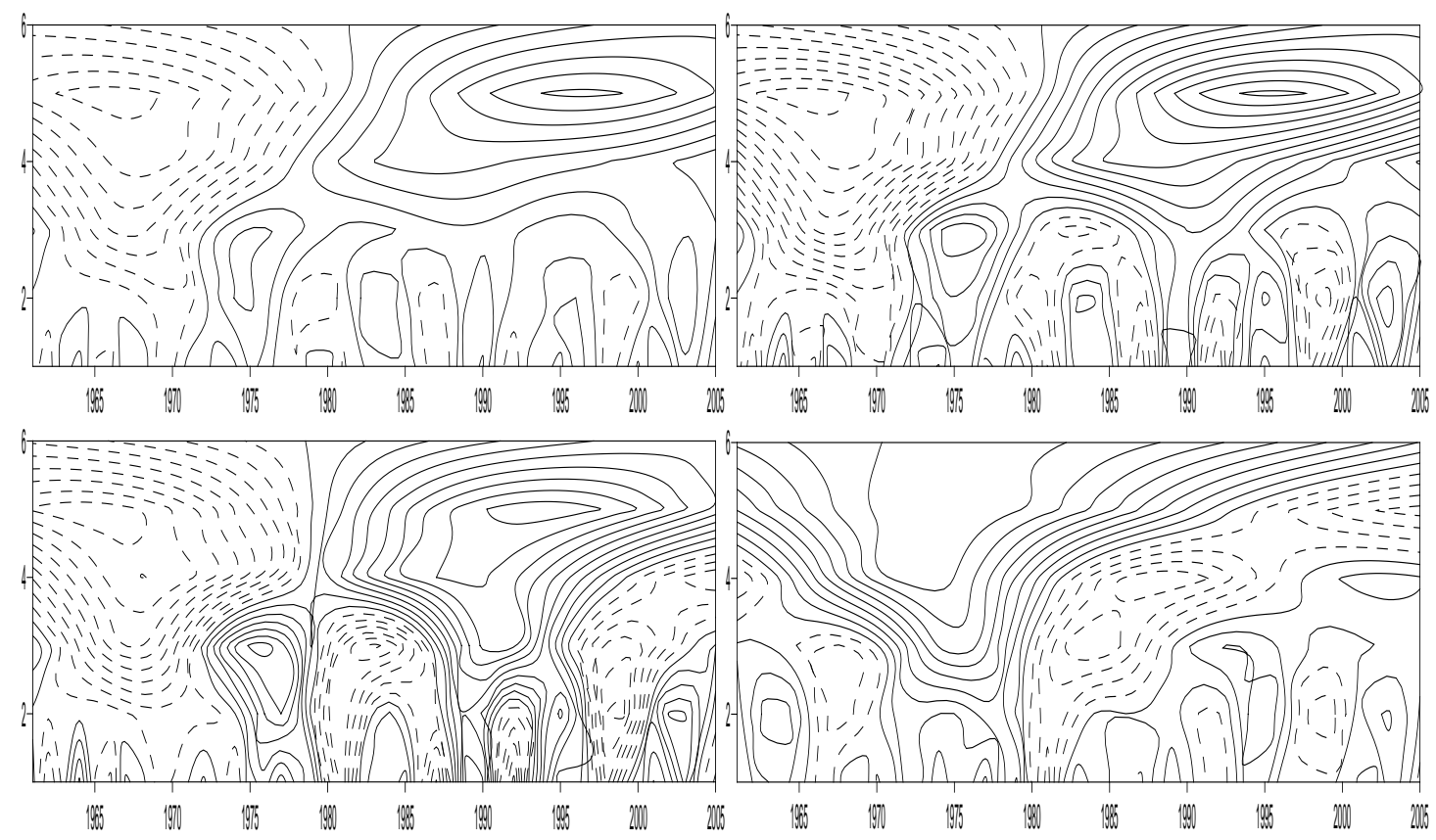

Fig.4 Wavelet analysys of annual fog days of Shanxi Province(a.the province,b.north region;c, the central region; d,south region)

In contrast to the wavelet transform graph of the fog day sequence, the characteristics of these fogs are well reflected in the graph. It is shown that the total number of fog in the whole province is at 32a time scale, the signal is stronger, there is an obvious 60a period, the period from 1961 to 1978 was the lowest, and the lowest in 1966. Since 1979, it has been more than a few years since 1979. After 2009, it will be a little less.

\section{The Background Conditions}

Based on 500hpa high situation, the circulation situation of fog can be divided into four classes: two trough a ridge type (47\%), a trough a ridge type (9\%), broad low $(40 \%)$, two groove ridge (double 
resistance) (4\%); Corresponding to the situation on the ground have equalizing type, high pressure impact type and trough type, including high pressure can be divided into the modified small high impact type,high pressure at the front, at the bottom of the (weak) at the bottom of the high pressure, reflux, reflux trough at the bottom of the front, high pressure, etc., at the back of the visible, closely related to the formation of the fog with the ground high pressure.
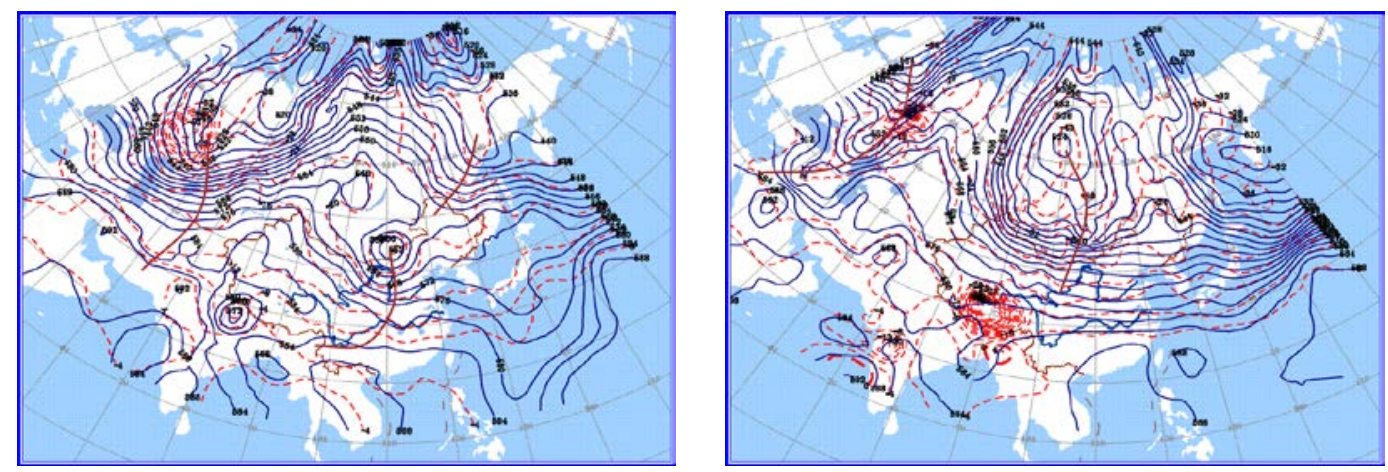

Fig.5 the 500hPa circulation situation at 20:00 on October 20, 23,1986

\section{Two Trough a Ridge Type (That is, The Single Type Resistance)}

There are two situations, one is a type of resistance, blocking high near Lake Baikal region, western groove wider, east of shanxi by the bottom of the tank or the front resistance high weak northwest by west airflow control, $24 \mathrm{~h}$ before the fog formation, $500 \mathrm{hpa}$ isotherm and almost parallel to the contour, the ground is weak type high pressure influence more, better conditions for formation water vapor, radiation cooling condition is better at night.
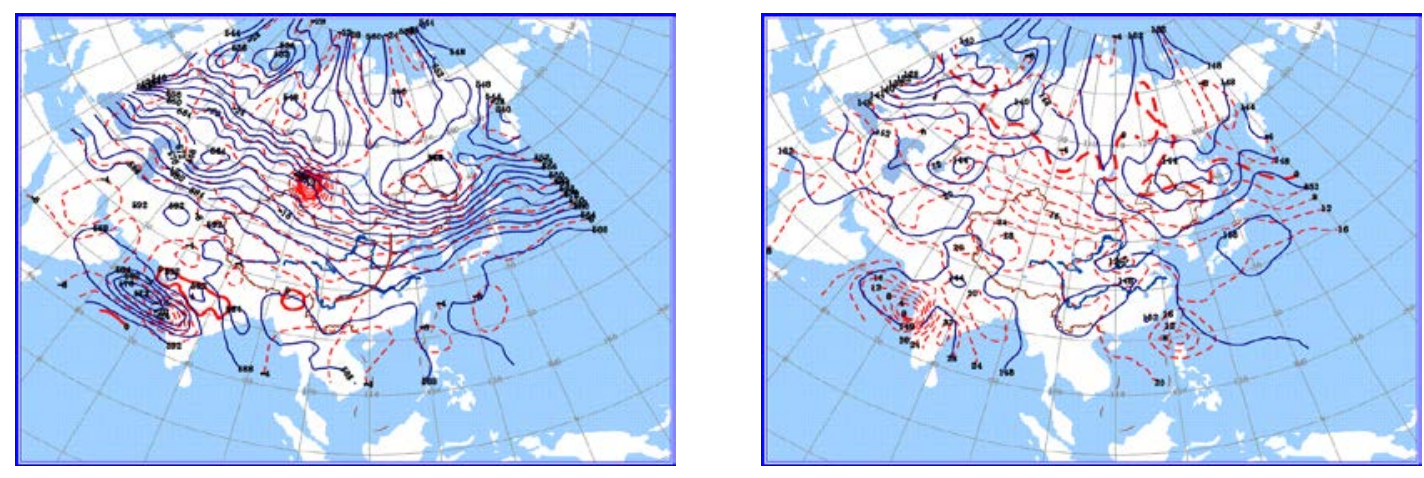

Fig.6 the 500hPa and 850hPa circulation situation at 20:00 on Sep. 20, 1986

\section{Broad Base Type}

Fog before 500 hpa high latitudes for broad low-value systems and control, in frontal zone located about $45 \sim 60$ DHS N, basic in the northwest - southeast direction, mid-latitude short-wave trough, Shanxi Province is located in the base at the bottom of the system, by the by west northwest air (water vapor condition is better) or weak (advection cooling airflow control, contour is sparse, with weak LengPing conveying flow to shanxi. 

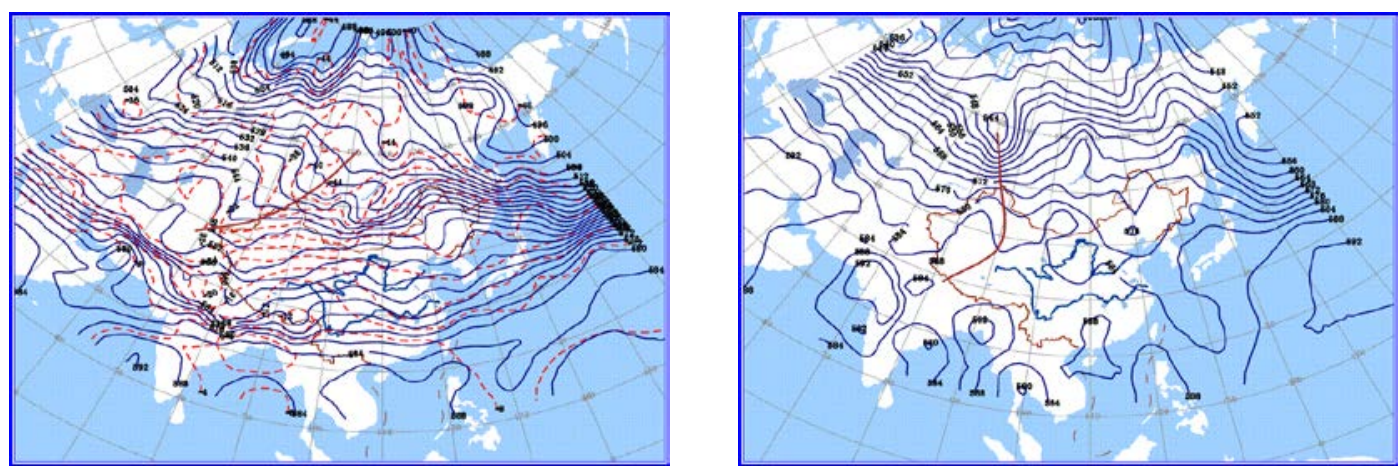

Fig.7 the 500hPa circulation situation at 20:00 on Jan. 8 and August 251989

\section{A Groove Ridge Type}

There are two cases, one type is a trough in the east (figure a), located in the east of the ural mountains region, and more wide, the downstream short-wave trough, shanxi with many weak southwest airflow control before short-wave trough, water vapor condition is good, but there are weak on 500 hpa LengPing input to shanxi, more appear in the central and southern shanxi, mainly concentrated in November.

The other is a slot type (FIG. B) in the west, slot is located in the region near the ural mountains, the east is weak ridge or subtropical high control, warm advection is obvious, mainly in the summer. This type appears less and lasts less.
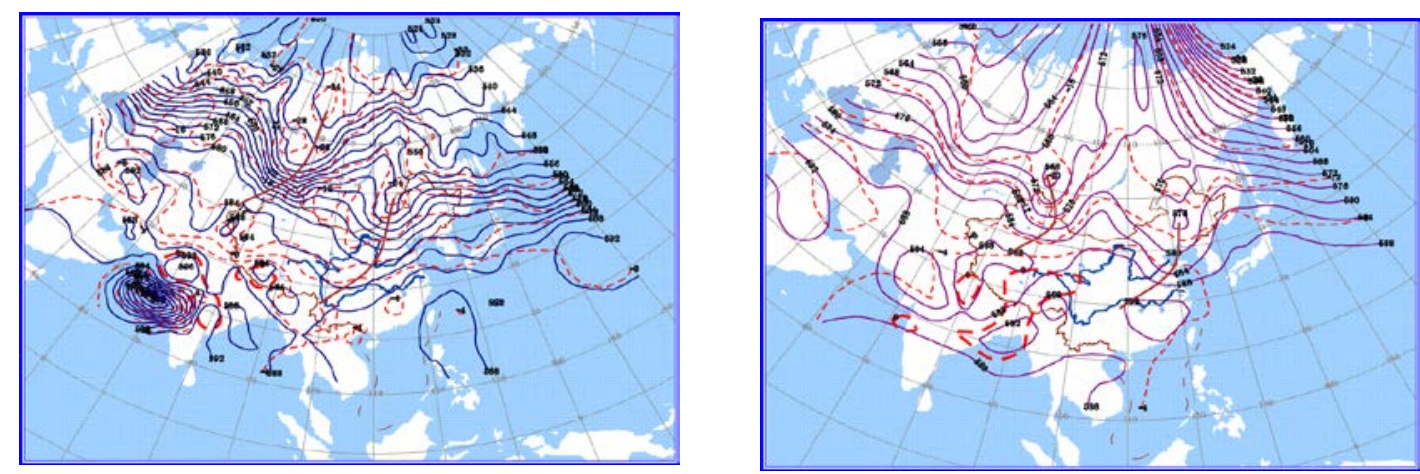

Fig.8 the 500hPa circulation situation at 20:00 on Sep.26 1990 and August 221998

\section{Two-Groove Two-Ridged Type}

Fog before 500 hpa circulation for double resistance, Lake Baikal and the ural mountains region respectively two blocking high, Lake Baikal resistance high before cut off the low pressure exists commonly, Shanxi Province is located in the cut off at the bottom of the low pressure or the front of the warm ridge, controlled by the northwest by west airflow or weak airflow, warm advection, the ground is weak at the bottom of the high pressure or at the front, or east north east, near formation water vapor cooling, causing the appearance of the fog.

\section{The Fog Forecast Method}

Fog is the surface layer of water vapor condensation phenomenon, and the unsaturated air saturated state, can be realized in two ways: one is the increased water vapor (humidifying), the other is to make the air cooling (cool). In addition, there is a stable atmosphere. Therefore, there are three factors to consider when predicting future fog. 
From the weather situation, the background of large scale circulation is analyzed, and the vast majority of fog occurs in the background of the weft circulation, the ground situation is the weak pressure field.

\section{Analyze the Stability of the Atmosphere.}

The humidity condition is analyzed. Formation water vapor condensation phenomenon because of the fog is near, the height of the fog is in commonly $400 \mathrm{~m}$ below the conditions for formation of humidity should be analyzed, therefore, generally look at 925 hpa and below layer humidity, due to the essential elements of boundary layer of NWP forecast accuracy is low, so a better indicator of the factors of the ground.

\section{The Maintenance and Strengthening of The Fog}

In the following circumstances, the fog will be maintained or strengthened

(1) In the autumn and winter season, there is already a wide range of fog. If there is no future strong cold air invasion or low cloud increase, the fog will remain.

(2) In the background of the circular flow of weft, the fog will be further developed or enhanced if the moisture field structure has a "wet" short-wave channel.

(3) In winter after a wide range of snow fog, if a high altitude long time controlled by the ridge, and high wind speed is small, the fog will maintain or develop.

\section{The Mist Decreases and Dissipates}

The condition of the fog dissipates in contrast to the conditions formed. When the fog is formed or the air is added to the water vapor, or the air is cooled to saturation; When it dissipates, it is either added to the dry air or the heat of the air. Generally speaking, wind enhancement and sunbeam enhancement can dissipate the fog.

\section{Conclusions}

1) The number of fogs is in the southeast, and the northwest is small. The fewest areas of fog day are not in the north, but in xingxian county, in the middle of the luliang area, at most in the southern city of xiangfen. In Shanxi Province, fog has occurred throughout the year, but mainly in the fall, about $40 \%$. The second is summer, accounting for $26 \%$; In the spring of the least; And individual stations (such as xingxian in central China) are mainly winter. In the whole province, the average annual fog is increasing gradually.

2) The circulation situation of fog can be divided into four classes: two trough a ridge type (47\%), a trough a ridge type (9\%), broad low (40\%), two groove ridge (4\%); Corresponding to the situation on the ground have equalizing type, high pressure impact type and trough type, including high pressure can be divided into the modified small high impact type, high pressure at the front, at the bottom of the (weak) at the bottom of the high pressure, reflux, reflux trough at the bottom of the front, high pressure, etc., at the back of the visible, closely related to the formation of the fog with the ground high pressure.

3) The forecast of fog can be forecast from the formation, maintenance and strengthening, weakening and dissipation.

\section{Reference}

[1]Liu yuying,LiYufan et al.The Climatic characteristics and causes of fog days in Jilin Province.2015,35(8):1060-1066

[2] Zhou heling,LiLiping et al.Climatic characteristics of fog in Hebei province and trend research.Meteorological monthly,2011,37(4):462-467

[3] Tao Yun,DuanXu,etal,.The change characteristics of fog in Yunnan during the nearly 50 years.Journal of Yunnan University,2011,33(3):308-316.issn:0258-7971 
[4] NiuShengjie,LuChunsong,etal.Advances in Fog Research in China.Advances in MET S\&T,2016,6(2):6-19

[5] LI Miao, MIAOAimei.WANG Hongxia.et al. Variation Characteristics of Fog Days with Different Intensity Ranges and Its Causes in Shanxi in Recent 33 Years[J]. Journal of Arid Meteorology, 2015, 33(2):249 -256, doi:10. 11755/j. issn:1006 -7639(2015) -02-0249

[6] Guo Lijun, Guo Xueliang.2016. The type, vertical structure and physical formation mechanism of persistent heavy fog events during 2009-2013 in the Beijing region [J]. Chinese Journal of Atmospheric Sciences (in Chinese), 40 (2): 296 310, doi:10.3878/j.issn.1006-9895.1505.14275.

[7] Li Zihua.Studies of Fog in China over the past 40 years.Acta Meteorologica Sinica.Vol.59,No.5.Oct..,2001:616-624 